cause the cyst to close by inducing inflammation by means of an injection of iodine; that Professor Gross stated that six methods of treatment were at the command of the surgeon, all more or less serviceable, but not one entirely free from danger; and that Professor Agnew apparently did not consider the subject of sufficient importance to necessitate a separate paragraph being given to it, ho having enumerated the various methods of treatment applicable to the several forms of goitre in one list, and in such a manner that only a person possessing a full and accurate knowledge of the subject could distinguish which method was suitable to a particular form of the disense. A closer examination of the treatment recommended would have shown me that in two of the three English works injection of tincture of iodine was favourably spoken of, but under different conditions, Mr. Erichsen having advised the cyst to be emptied before the iodine was injected, whereas Mr. Bryant advocated the injection of tincture of iodine and alcohol in equal parts, without any allusion to the preliminary measures recommended by Mr. Erichsen; and that Professor Gross, on the other hand, whilst stating that injections of iodine occasionally succeed, went on to say that the cperation was liable to be followed by severe inflammation, eventuating in rapid reaccumulation and was in the main less certuin than the use of a seton, whereas Mr. Bryant stated that this latter method was dangerous, and should only be adopted when simple means were unavailing and further interference necessary. With such diversity of opinion it would have been extremely difficult for me to come to a couclusion as to what was the best course to adopt, especially as the weight of opinion was against the treatment which seemed most rational, and 1 consider that had I seleeted an operation which necessitated the exposure of my patient to considerable risk, the responsibility for the course adopted would have rested on the shoulders of most of the authors of the surgical works which deal with this disease, rather than on my own.

Considering the frequency with which cases of cystic goitre are mer with, and the large number of deaths which have followed the attempts to effect a cure, I maintain that the treatment of this disease demands more serious attention than surgeons have hitherto accorded it.

\section{LAPAROTOMY FOR TUBERCULAR PERITONITIS.}

TWO CASES OF IAPAROTOMY FOR ASCITES CAUSED BY TURERCULAR PERITONITIS; BOTH CURED.

\section{BY JOHN HOMANS, M.D.,}

SURGEON TO THE MASSACHUSETTS GENERAL HOSPITAL, AND HARYARD UNIVERSTTY LECTURER ON THE DIAGNOSIS AND TREATMENT

$$
\text { OF OVARIAN TUMOURS. }
$$

IN The LANCET for Nov. 5th, 1887, is an excellent report of a very interesting discussion at the Clinical Society of London. Mr. Lawford Knaggs does me the honour to refer to a case of mine in connexion with one of Sir Spencer Wells's, albeit I figure as Dr. "Hornan." In tracing the subsequent history of my patients after they have left my hands I have found another case, and both seem to me worth publishing.

In June, 1884, Dr. Tower of South Weymouth, sent me a pale, thin, emaciated girl, twenty-one years old, with a large abdomen full of fluid. Her weight was $90 \mathrm{lb}$. There was no swelling of the feet. The catamenia had been absent four months, and the girl seemed near her end from general failure of her constitution. I opened the abdomen on June 19th, 1884, and removed about $12 \mathrm{lb}$. of ascitic fluid. The stomach, apparently distended by fluid, I found as a large tumour in the upper portion of the abdomen; it was about ten inches in diameter Owing to lymph and adhesions the spleen and liver could not be felt. Much lymph covered the peritoneum in flakes and layers, and lay upon the abdominal viscera The peritoneum was studded over with little white deposits of tubercles, and nodules were also seen. A piece of the peritoneum was cut out and sent to a pathologist, who reported that the deposits were tubercles, but that the bacillus had not been found. In short, the disease was what we have always called tubercular peritonitis. The abdomen was sponged out as thoroughly as could be done without disturbing the viscera more than was thought prudent, and the wound was closed without the insertion of a drainage tube And here let me say that I have never been able to establish an artificial drain in a case of ascites by the insertion of a drainage tube. I have tried to do this again and again, but have never succeeded. When Nature means to cure the patient by drainage she reopens the wound. The suture were removed on the eighth day, and the wound was found united. In about ten days more the abdomen had become distended with fluid, and on July 7th the scar opened and the fluid ran out, and continued to do so. On July 12th the patient went home in good spirits. The ascitic fluid continued to run out, but was not offensive, and I suppose not septic. In November, 1884, she had gained considerable flesh, and had a good appetice. In February, 1885, the catamenia, which had been absent a year, reappeared, and the ascitic discharge was much diminished. In May the amount of discharge was very slight and she was able to walk out of doors; she was married in June. I saw her in January, $1886^{\circ}$; sh $\theta$ was fat and strong and was doing her housework; her weight was $121 \mathrm{lb}$. I received a visit from my patient again in November, 1886 ; she then weighed $130 \mathrm{lb}$, and was quite strong. She had never been pregnant. There was a slight sinus, which discharged about a drachm of pus a day. The case seemed to me at the time, and seems to $m \in$ now, a wonderful recovery.

The second case is one in which the patient was not emaciated, and in which I had expected to find an ovarian or parovarian cyst. The patient was a school-girl, seventeen years old, of healthy appearance. Her complexion was pale. Her umbilical girth was thirty-four inches, and thought I felt a very faint aortic impulse. The catamenia were normal. She was sent to me in April, 1887, by Dr. Kingsbury, of Lyme, New Hampshire. The abdomen had begun to enlarge twelve months before, and the process of enlargement had been slow. On opening the peritoneum on April 20th, 1887, ascitic fluid ran out, and on further investigation the whole abdominal cavity was found to be studded with small hard whitish nodules. They were on the uterus, intestines, and parietal surface of the peritoneum. both ovaries, and Fallopian tubes. One tube thickly studded with tubercles, with its corresponding ovary, was removed. The peritoneal cavity was carefully sponged out, but the ascitic fluid seemed to reaccumulate so fast that a glase drainage tube was put in and the abdomen closed. The. specimens were sent to Professor Fitz, who reported that the deposits were tubercular. Only about an ounce of fluid in twenty-four hours was obtained from the drainage tube, and on the third day it was removed. The patient went home at the end of three weeks. On December 28th, 1887, eight months after the operation, I had a letter from Dr. Kingsbury, in which he says that the abdomen is no larger than natural; that she has no fever, pain, tenderness, or unpleasant sensations in the abdomen; and that her appetite is good. She is not very strong, but can endure more than before the operation; she does some light work in the family and gives lessons in music.

The second case is not as remarkable as the first, but perhaps both will aid in the study of the treatment of tubercular peritonitis by laparotomy.

\section{NOTE ON THREE CASES OF OBLITERATIVE ARTERITIS.}

BY W. B. HADDEN, M.D.LoND., M.R.C.P. assigTaNT PHYSIClay aND DEMONSTRaTOR OF MORBID ANaTOMY TO ST. THOMAS'S HOSPITAL, ASSISTANT PHYSICLAN TO THE HOSPITAL FOR SICK CHITDREN.

THE disease known as "obliterative arteritis" is by no means common, and its pathological nature is still uncertain The case which I am about to describe is unfortunately incomplete. I only saw the patient once, but I satisfied myself that the affection was identical with that described by Mr. Pearce Gould and by myself in vol. xvii. of the Clinical Society's Transactions:

The patient was a fairly robust young man, aged ninteen, a rug-sorter by trade. He came to me as an out-patient at St. Thomas's Hospital on December 10th, 1887, complaining

1 This case may be found briefiy reported in a little book entitled. "Three hundred and eighty-four Laparotcmies for various Disezses," by John Homans, Boston, 1887. 